\title{
A new role for interferon gamma in neural stem/ precursor cell dysregulation
}

\author{
Janine Walter ${ }^{1 *}$, Silke D Honsek ${ }^{2,3}$, Sebastian Illes ${ }^{1}$, Jennifer M Wellen ${ }^{1}$, Hans-Peter Hartung ${ }^{1}$, Christine R Rose ${ }^{2}$, \\ Marcel Dihné
}

\begin{abstract}
Background: The identification of factors that compromise neurogenesis is aimed at improving stem cell-based approaches in the field of regenerative medicine. Interferon gamma (IFN $\gamma$ ) is a main pro-inflammatory cytokine and up-regulated during several neurological diseases. IFNy is generally thought to beneficially enhance neurogenesis from fetal or adult neural stem/precursor cells (NSPCS).

Results: We now provide direct evidence to the contrary that IFNy induces a dysfunctional stage in a substantial portion of NSPC-derived progeny in vitro characterized by simultaneous expression of glial fibrillary acid protein (GFAP) and neuronal markers, an abnormal gene expression and a functional phenotype neither typical for neurons nor for mature astrocytes. Dysfunctional development of NSPCs under the influence of IFN $\gamma$ was finally demonstrated by applying the microelectrode array technology. IFN $\gamma$ exposure of NSPCs during an initial 7-day proliferation period prevented the subsequent adequate differentiation and formation of functional neuronal networks.

Conclusions: Our results show that immunocytochemical analyses of NSPC-derived progeny are not necessarily indicating the correct cellular phenotype specifically under inflammatory conditions and that simultaneous expression of neuronal and glial markers rather point to cellular dysregulation. We hypothesize that inhibiting the impact of IFNy on NSPCs during neurological diseases might contribute to effective neurogenesis and regeneration.
\end{abstract}

\section{Background}

Neural stem/precursor cells (NSPCs) may be useful as an endogenous or transplantable source of newly generated neural cells, which can replace lost or diseased neurons within the central nervous system (CNS) [1]. A prerequisite for this is an appropriate functional differentiation of immature neural cells into electrophysiologically active neurons. As nearly all CNS diseases involve acute and chronic inflammatory processes [2], it is crucial to understand NSPC development under inflammatory conditions to better realize their full potential. IFN $\gamma$ is a key inflammatory cytokine, mainly produced by cytotoxic $\mathrm{CD}^{+}{ }^{+} \mathrm{T}$-cells and natural killer cells in the course of neurological diseases like cerebral traumata [3], stroke [4] or multiple sclerosis [5]. Beside

\footnotetext{
* Correspondence: Janine.Walter@googlemail.com

'Department of Neurology, Heinrich-Heine-University, Moorenstr. 5, 40225 Düsseldorf, Germany

Full list of author information is available at the end of the article
}

the observation that IFN $\gamma$-activated microglial cells induce neurogenesis [6], IFN $\gamma$ has also been reported to exert beneficial, pro-neurogenic effects on NSPC development in vitro and in vivo in a number of recent publications independently of microglial cells [7-9]. However, a hint that IFN $\gamma$ might be involved in potentially harmful developmental dysregulation was detected in a number of reports [10-12] and from its tumorinitiating role, since embryonic mice over-expressing IFN $\gamma$ develop medulloblastomas [13], indicating that IFN $\gamma$ may also be involved in malignant transformation of neural precursor cells.

In the present study, we demonstrated that IFN $\gamma$ induces an abnormal immunocytochemical phenotype in NSPCs with simultaneous expression of neuronal and glial markers. Furthermore, IFN $\gamma$ led to a dysregulated gene expression as well as dysfunctional electrophysiological properties. Additionally, we finally present evidence that IFN $\gamma$ exposure to NSPCs during an initial 7-day
C Biomed Central

() 2011 Walter et al; licensee BioMed Central Ltd. This is an Open Access article distributed under the terms of the Creative Commons Attribution License (http://creativecommons.org/licenses/by/2.0), which permits unrestricted use, distribution, and reproduction in any medium, provided the original work is properly cited. 
proliferation period dramatically impairs the subsequent development of functional neuronal networks as recorded by the microelectrode array technology. Our data clearly indicate that IFN $\gamma$ compromises neurogenesis. Thus, its role during inflammatory processes should be reassessed and IFN $\gamma$ suppression during brain pathology possibly supports functional neurogenesis.

\section{Results}

IFN $\gamma$ receptors 1 and 2 are expressed in NSPCs and their differentiated progeny

Experiments were performed either with proliferating NSPCs under the influence of growth factors which expressed immature neural markers like Sox2 and nestin (Figure 1A) or with the differentiated progeny of NSPCs that lost their immature markers and instead expressed $\beta$ III-tubulin or GFAP (Figure 1B). The signal transduction process of the proinflammatory cytokine IFN $\gamma$ starts with binding to the IFN $\gamma$ receptor (IFNGR). This receptor comprises two ligand-binding IFNG-R1 chains which are associated to two signal-transducing IFNG-R2 chains. Both domains of the receptor belong to the class II cytokine receptor family. To study effects of IFN $\gamma$ on NSPCs and their differentiated progeny, we confirmed the expression of IFNG-R1 and IFNG-R2 in proliferating or differentiated NSPC cultures (Figure 1). We performed immunocytochemical experiments to demonstrate the expression on protein level (Figure 1B). Then we compared the mRNA expression levels of both receptor domains by means of real-time quantitative PCR in various mouse tissues in comparison to proliferative or differentiated NSPCs (Figure 1C). Our results indeed confirmed the presence of both receptor domains in proliferative as well as differentiated NSPCs.

\section{IFN $\gamma$ reduces the population extent of NSPCs}

To investigate effects of IFN $\gamma$ on the extent of NSPC populations we performed an MTT-assay. We could

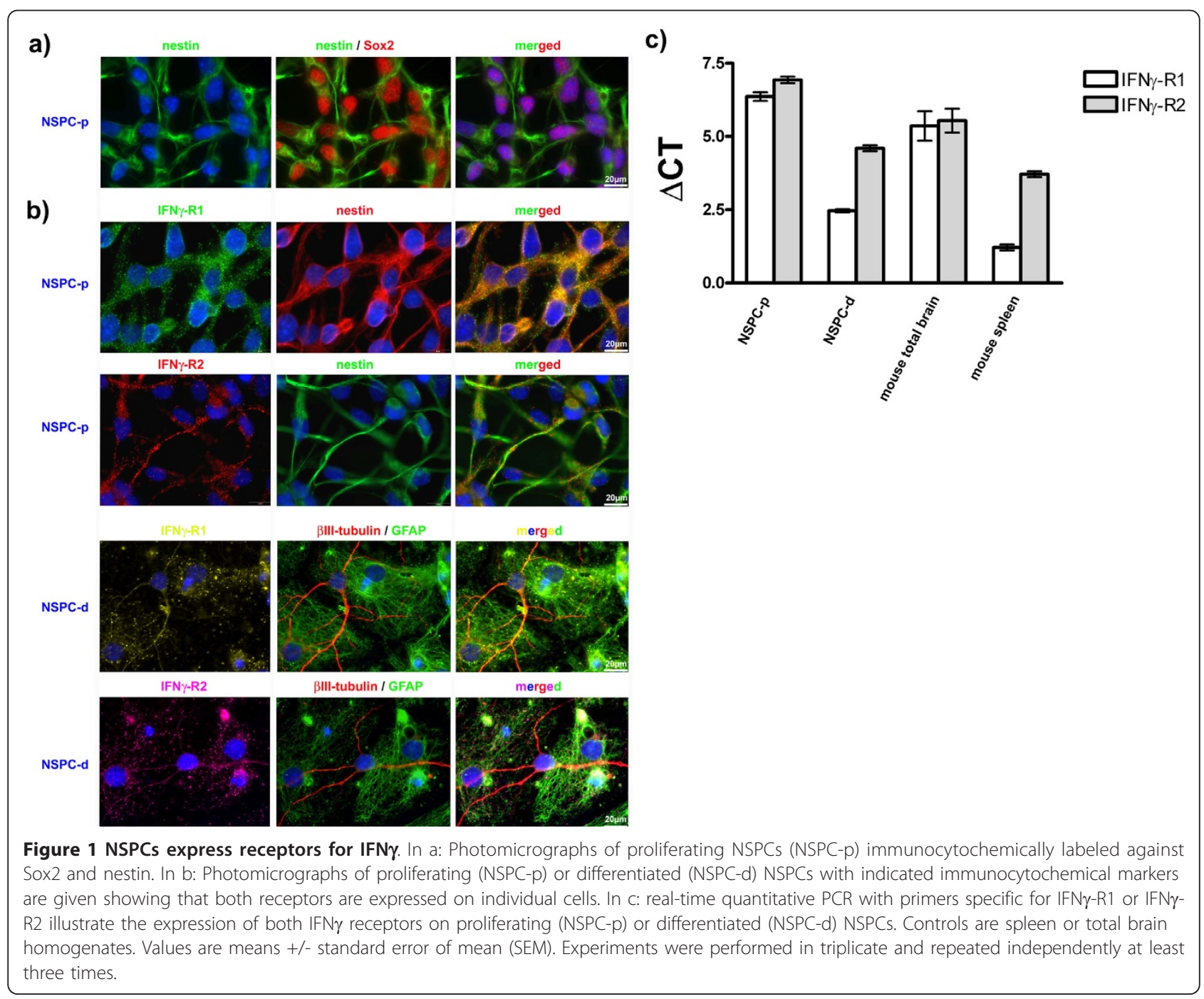


demonstrate that 100 or 1000 Units of IFN $\gamma / \mathrm{ml}$ led to significant reductions in the population extent during 48 hours under proliferative conditions (Figure 2A). To verify whether cytotoxic or apoptotic mechanism were involved, we verified caspase 3/7 activity during IFN $\gamma$ exposure and found a significant increase when caspase activity was measured by means of the Caspase-Glo 3/7 assay (Figure 2B). Also an increased immunocytochemical labeling against caspase $3 / 7$ protein (Figure $2 \mathrm{C}$ ) suggested an induction of apoptotic pathways in NSPCs after IFN $\gamma$ treatment. To detect possible anti-proliferative influences of IFN $\gamma$ on NSPC populations, we performed BrdU labelings. Here, we were able to detect an additional slight but significant anti-proliferative effect of IFN $\gamma$ (Figure 2D). Together, these data show that IFN $\gamma$ exerts apoptotic and anti-proliferative effects on NSPCs that together lead to reduced population extents even under the influence of FGF-2.

\section{IFN $\gamma$ induces an abnormal phenotype in NSPCs}

In the present study, we found that IFN $\gamma$ treatment of proliferative murine E14 neurosphere-derived NSPCs caused up-regulation not only of transcripts for $\beta$ IIItubulin or microtubule-associated protein 2a-c (MAP2ac), established markers for post-mitotic neurons, but also for the astrocyte marker glial fibrillary acidic protein (GFAP), challenging the prevalent view of a predominatly pro-neurogenic effect of IFN $\gamma$. At the same time, IFN $\gamma$ executed a down-regulation of CD133, a marker for immature NSPCs, which indicated a robust activation of differentiation programs despite the presence of growth factors (Figure 3A). Immunocytochemical experiments confirmed these results: on the one hand, we could detect an anti-proliferative effect of IFN $\gamma$ as numbers of $\mathrm{BrdU}^{+}$cells decreased (Figure 2D). On the other hand, we detected a robust increase in the number of cells expressing neuronal and glial specific proteins after IFN $\gamma$ treatment (Figure 3B). Surprisingly, in addition to $\mathrm{GFAP}^{-} / \beta$ III-tubulin ${ }^{+}$or $\mathrm{GFAP}^{+} / \beta \mathrm{III}$-tubulin ${ }^{-}$cells, a considerable number of NSPCs (39.3 \pm $14.5 \%$ of all cells) co-expressed GFAP and $\beta$ III-tubulin after a 3-day treatment with $1000 \mathrm{U} / \mathrm{ml}$ IFN $\gamma$ (Figure $3 \mathrm{~B})$. $\mathrm{GFAP}^{+} / \beta$ III-tubulin ${ }^{+}$cells in comparable numbers were also detectable after IFN $\gamma$ treatment with only 100 $\mathrm{U} / \mathrm{ml}$ (Figure 3B). Using a concentration of $100 \mathrm{U} / \mathrm{ml}$ IFN $\gamma$ led to a slightly weaker induction of GFAP and $\beta$ III-tubulin immunoreactivity in individual cells while numbers of cells showing at all this phenomenon were similar with 100 or $1000 \mathrm{U} / \mathrm{ml}$. This phenomenon was absolutely rare $(<0.01 \%)$ in the absence of IFN $\gamma$ (Figure $3 \mathrm{~B})$. In addition, IFN $\gamma$ treatment induced simultaneous expression of GFAP and the post-mitotic neuronal markers MAP2a-c in a large percentage of cells (GFAP $\left.+/ \mathrm{MAP} 2 \mathrm{a}-\mathrm{c}^{+}: 73.6 \pm 5.7 \%\right)$, illustrating that the co- expression of glial and neuronal markers is not restricted to $\beta$ III-tubulin. We next investigated the influence of IFN $\gamma$ treatment during a 7-day differentiation period after growth factor withdrawal from NSPC cultures to elucidate effects on cell maturation. Again, we detected cells co-expressing GFAP and $\beta$ III-tubulin (Figure 4A). Moreover, numbers of GFAP $^{-} / \beta$ III-tubulin ${ }^{+}$or $\mathrm{GFAP}^{+} / \beta$ III-tubulin ${ }^{-}$cells in IFN $\gamma$ treated cultures differentiated for 7 days were significantly lower than without IFN $\gamma$ Figure 4A), which is in direct contrast to the expected pro-neurogenic role of IFN $\gamma$. As terminal neuronal differentiation could take longer than 7 days, we also cultured NSPC populations without growth factors for 14 or 21 days under the influence of IFN $\gamma$. Also here we found $\mathrm{GFAP}^{+} / \beta$ III-tubulin ${ }^{+}$cells indicating that this phenotype is stable during 14 or 21 days under differentiation conditions (data not shown). To verify if this phenomenon depends on more restricted precursors being present in neurosphere-derived populations, we generated homogenous cultures of multipotent neural stem cells (NS cells). These populations were generated from murine embryonic stem cells. Also in NS cell cultures, $\mathrm{GFAP}^{+} / \beta \mathrm{III}$-tubulin ${ }^{+}$cells were induced even though the part of NS cell-derived $\mathrm{GFAP}^{+} / \beta$ III-tubulin ${ }^{+}$ cells was smaller in comparison to neurosphere-derived $\mathrm{GFAP}^{+} / \beta$ III-tubulin ${ }^{+}$cells. This shows that IFN $\gamma$ can generate this abnormal phenotype from immature neural stem cells independently of the presence of neuronal or glial precursors (Figure 4B). Thus, our experiments suggest that IFN $\gamma$ can drive the differentiation of NS cells or NSPC populations towards an immunocytochemically abnormal marker profile, indicating a genetic and/or functional dysregulation.

\section{IFN $\gamma$ induces an abnormal down-stream signaling in NSPCs}

To study changes in IFN $\gamma$ receptor expression, we performed quantitative real-time PCR after a 3-day IFN $\gamma$ treatment of proliferative NSPCs. We detected increases in the transcript numbers of IFN $\gamma$-receptor 1 and IFN $\gamma$ receptor2 (Figure 5A), as well as the IFN $\gamma$-related downstream factor signal transducers and activators of transcription 1 (Stat1). However, inducible nitric oxide synthase (iNOS), a gene product, which is usually upregulated as a result of IFN $\gamma$ signaling, was down-regulated, revealing another surprising effect of IFN $\gamma$ on NSPCs (Figure 5A). We investigated IFN $\gamma$-induced changes of pro-neural basic helix-loop-helix (bHLH) genes and the neurogenic transcription factor Pax6, which are important for neuronal determination. Supporting the notion that IFN $\gamma$ does not promote neuronal determination, we found that Math1, Mash1, Neurogenin 1 and Pax6 were down-regulated in NSPCs after IFN $\gamma$ treatment (Figure 5B). Further, while IFN $\gamma$ 


\section{a)}

population extent after IFN $\gamma$ treatment

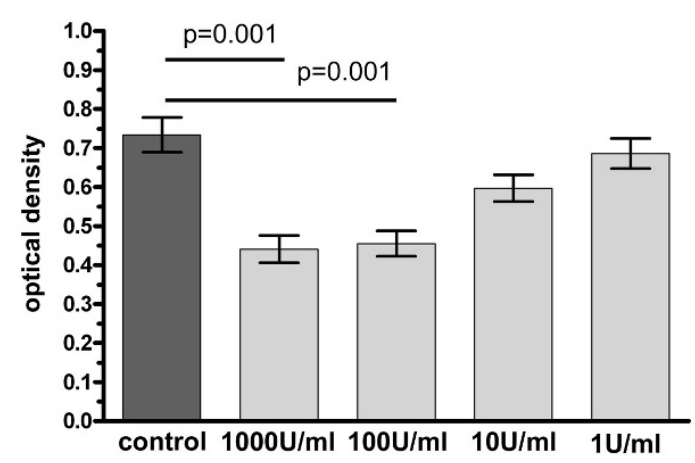

b)

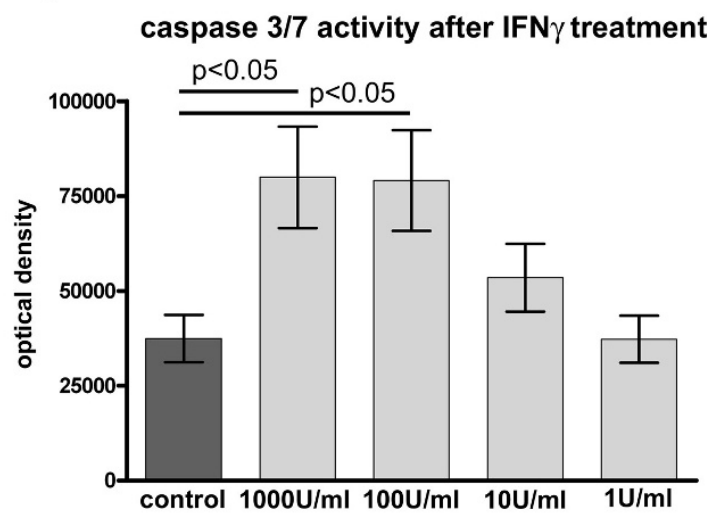

c)

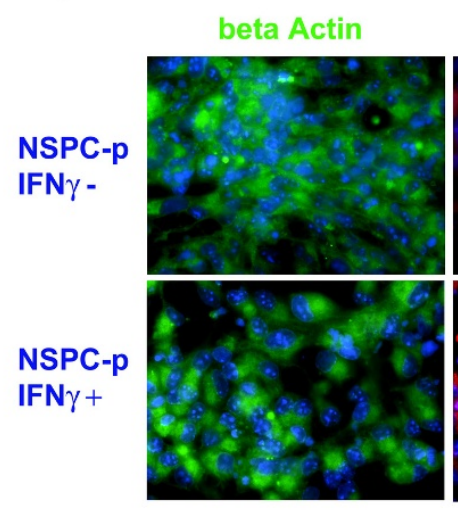

E14 neurosphere-derived cells
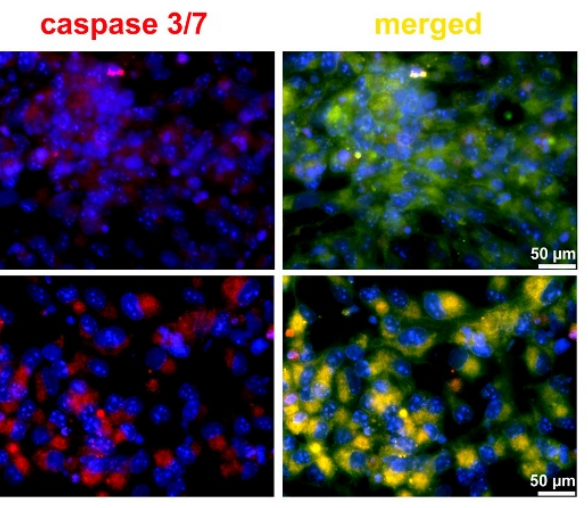

d)

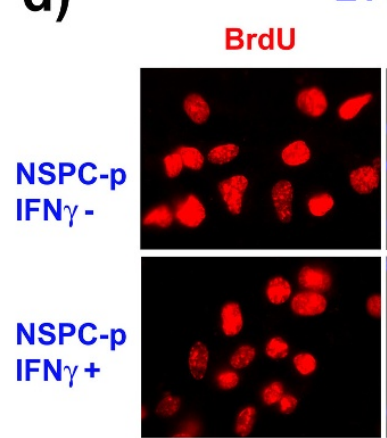

E14 neurosphere-derived cells
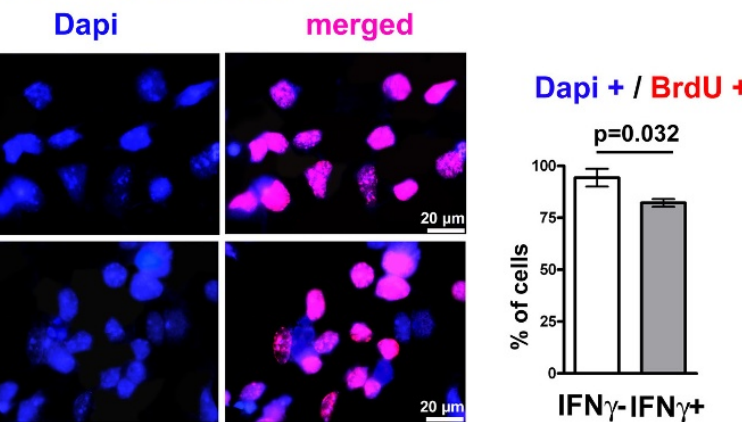

Figure 2 IFN $\gamma$ reduces the population extent of NSPCs. In a: Optical densities [9] correlate to the extent of NSPC populations after a 48-hour IFN $\gamma$ treatment with indicated concentrations. Values are means +/- standard error of mean (SEM). Experiments were performed in triplicate and repeated independently at least three times. In b: Optical densities correlate to caspase 3/7 activity after a 48-hour IFN $\gamma$ treatment with indicated concentrations. Values are means $+/$ - standard error of mean (SEM). Experiments were performed in triplicate and repeated independently at least three times. In c: Photomicrographs of caspase 3/7 immunocytochemistries are given for proliferating (NSPC-p) NSPCs with or without IFNy treatment. Beta Actin labeling visualizes cytoplasmatic structures to better correlate the caspase 3/7 signal to single cells. In d: Photomicrographs of BrdU labelings are given to visualize the amount of proliferating cells with or without IFN $\gamma$ treatment. Additionally, quantification of BrdU ${ }^{+}$ cells is given. Values are means $+/$ - standard error of mean (SEM). Experiments were performed in triplicate and repeated independently at least three times. $\mathrm{DAPl}^{+}$nuclei are given in blue. 


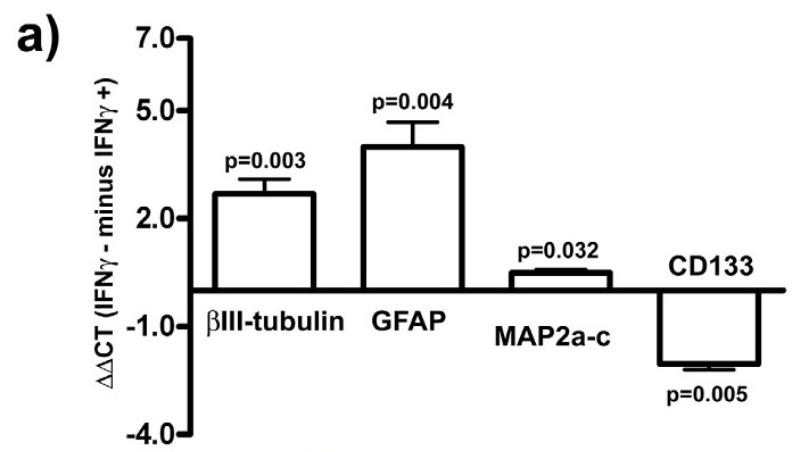

b)

E14 neurosphere-derived cells

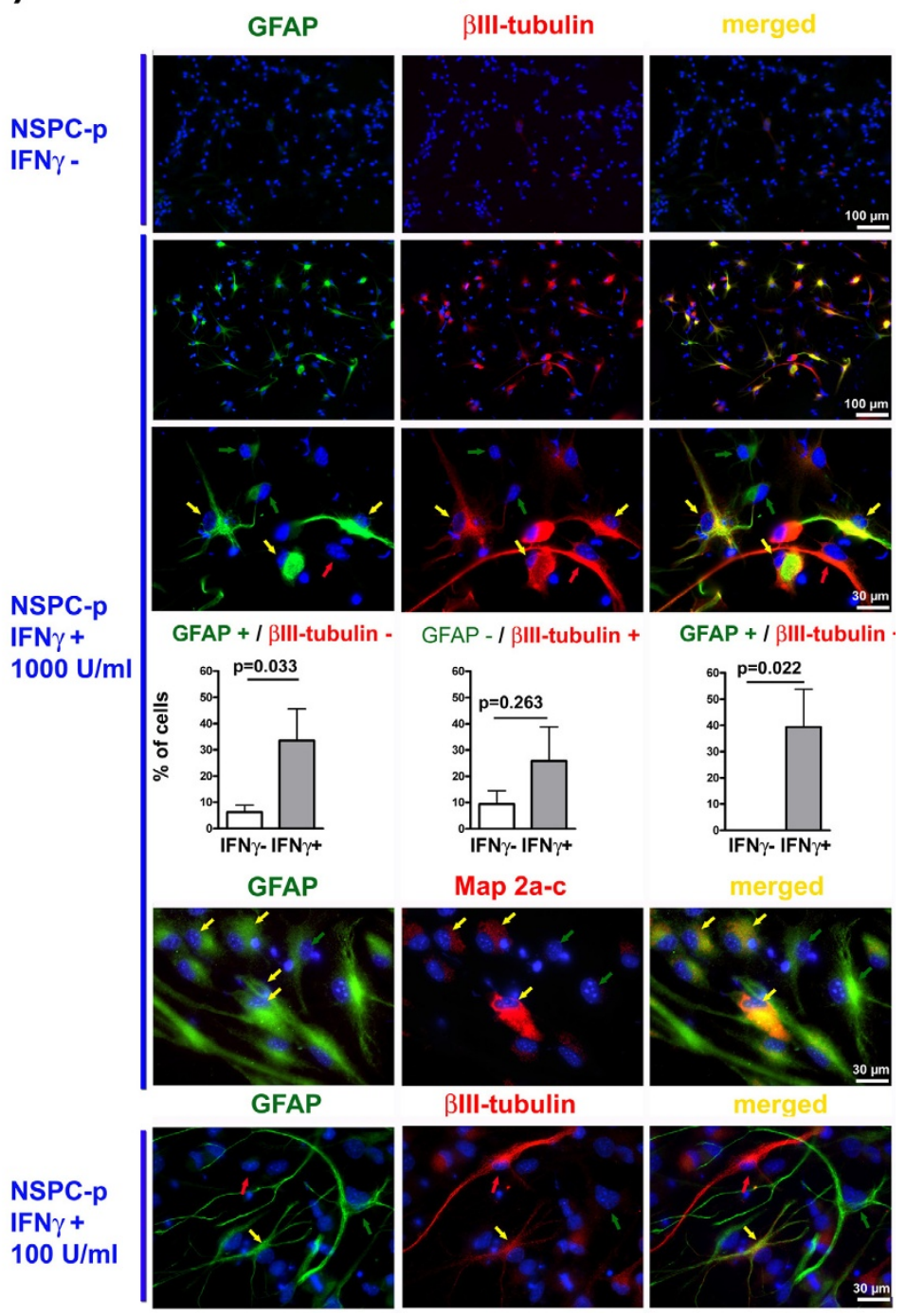

Figure 3 Cell type-specific marker expression after IFN $\gamma$ treatment under proliferative conditions. In a: Results from real-time quantitative PCRs expressed as $\triangle \triangle C T$ (IFN $\gamma$ - minus IFN $\gamma+$ ) of PBS-treated control and IFN $\gamma$-treated groups for the indicated markers of proliferating NSPCs. Higher values indicate a higher gene expression. Values are means + - standard error of mean (SEM). Experiments were performed in triplicate and repeated independently at least three times. In b: Photomicrographs of proliferating NSPCs (NSPC-p) with indicated immunocytochemical markers (GFAP, $\beta$ III-tubulin, Map2a-c). Yellow arrows mark GFAP $/ \beta \|$ II-tubulin ${ }^{+}$cells, the red arrow marks a GFAP $/ \beta \|$ ll-tubulin ${ }^{+}$neuron and green arrows mark GFAP ${ }^{+} / \beta \| l$-tubulin ${ }^{-}$astrocytes. DAPI ${ }^{+}$nuclei are given in blue. Diagrams show the percentages of immuno-positive cells from all DAPI ${ }^{+}$-cells with (IFN $\gamma+$ ) or without (IFN $\gamma$-) IFN $\gamma$ treatment as indicated. Values are means $+/$ - standard error of mean (SEM). Experiments were performed in triplicate and repeated independently at least three times. 


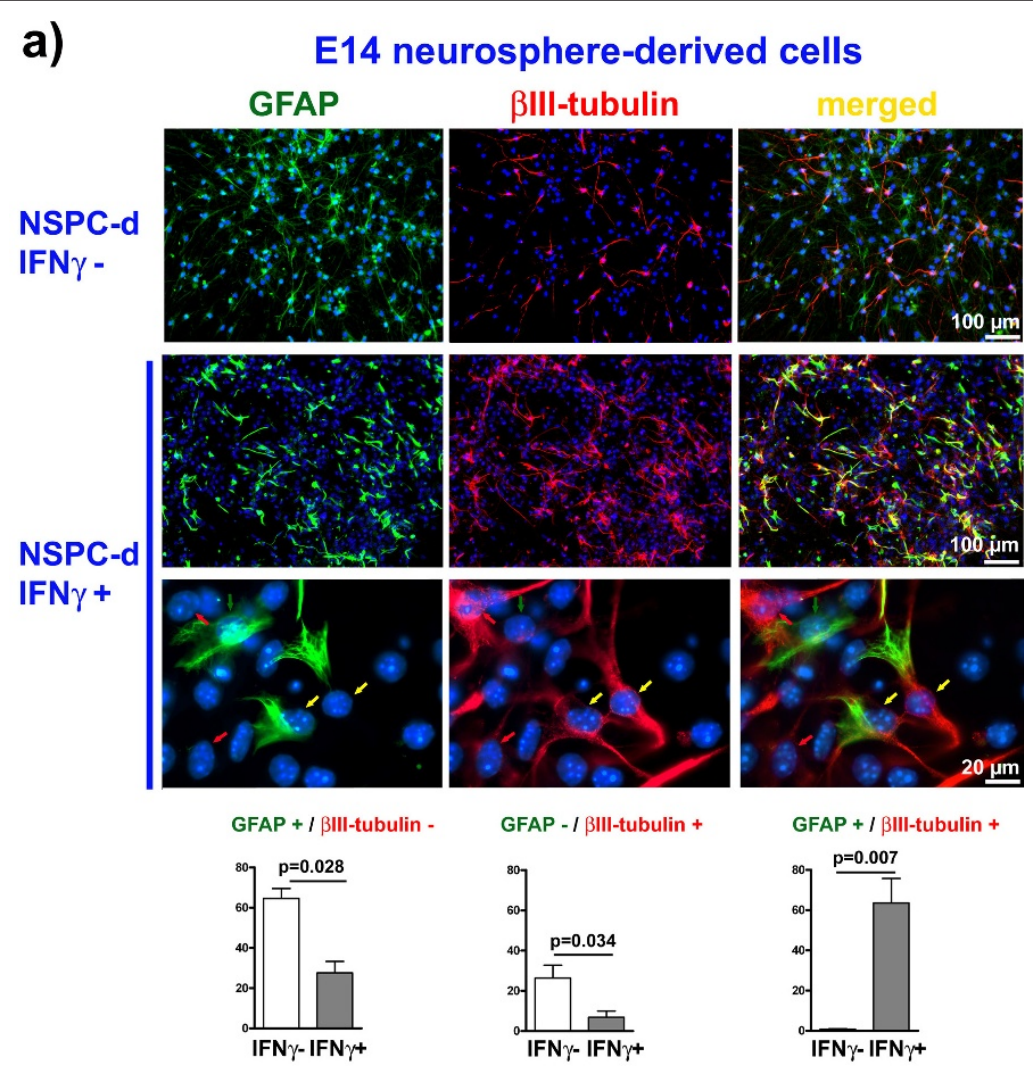

b)

\section{NS cell-derived cells}
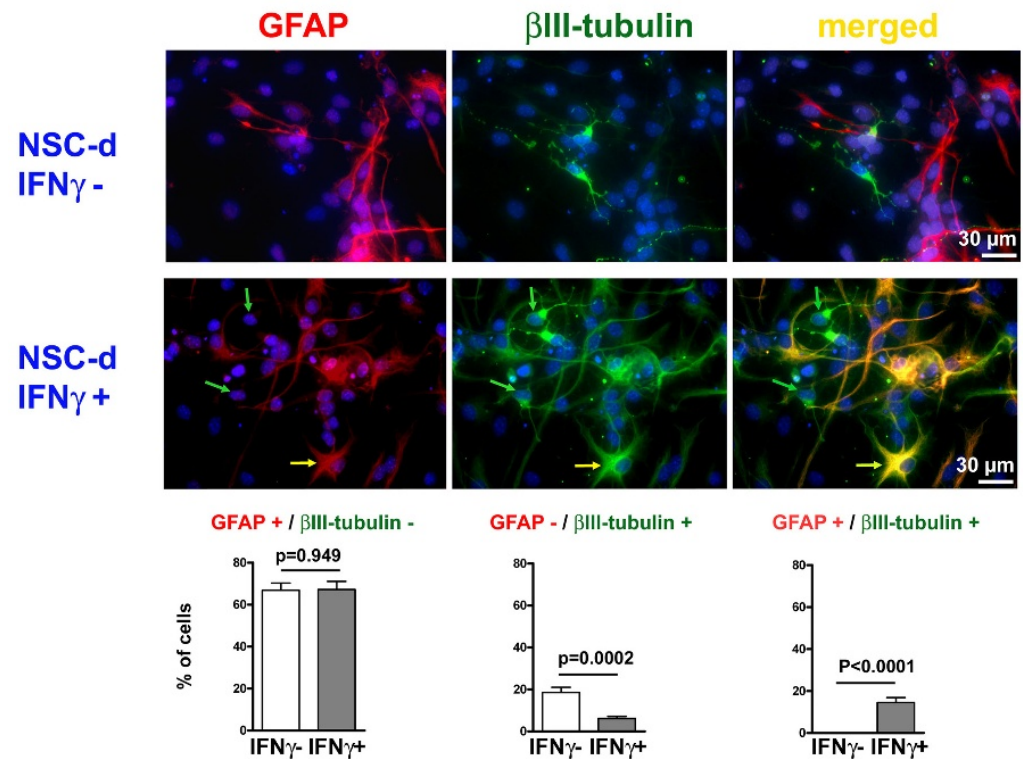

GFAP - / ßIII-tubulin +

GFAP + / BIII-tubulin +

Figure 4 Cell type-specific marker expression after IFN $\gamma$ treatment during differentiation. In a: Photomicrographs of NSPC populations after a differentiation period of 7 days (NSPC-d) are given with indicated immunocytochemical markers and the corresponding quantification of immuno-positive cells from all DAPI ${ }^{+}$cells with (IFN $\gamma+$ ) or without (IFNy-) IFN $\gamma$ treatment as indicated. Values are means $+/$ - SEM. Experiments were performed in triplicate and repeated independently at least three times. In b: Photomicrographs of mouse embryonic stem cell-derived neural stem cells (NS cells) differentiated for 7 days (NSC-d) with indicated immunocytochemical markers with (IFN $\gamma+$ ) or without (IFN $\gamma$-) IFN $\gamma$ treatment are given. Yellow arrows mark GFAP $/ \beta$ III-tubulin ${ }^{+}$cells. Red arrows mark GFAP $/ \beta \| l$-tubulin neurons and green arrows mark GFAP/ $\beta$ III-tubulin ${ }^{+}$astrocytes. Note the untypical morphology of $\mathrm{GFAP}^{+} / \beta$ III-tubulin ${ }^{+}$cells under IFN $\gamma$ treatment in comparison to control. Values are means $+/$ - standard error of mean (SEM). Experiments were performed in triplicate and repeated independently at least three times. 


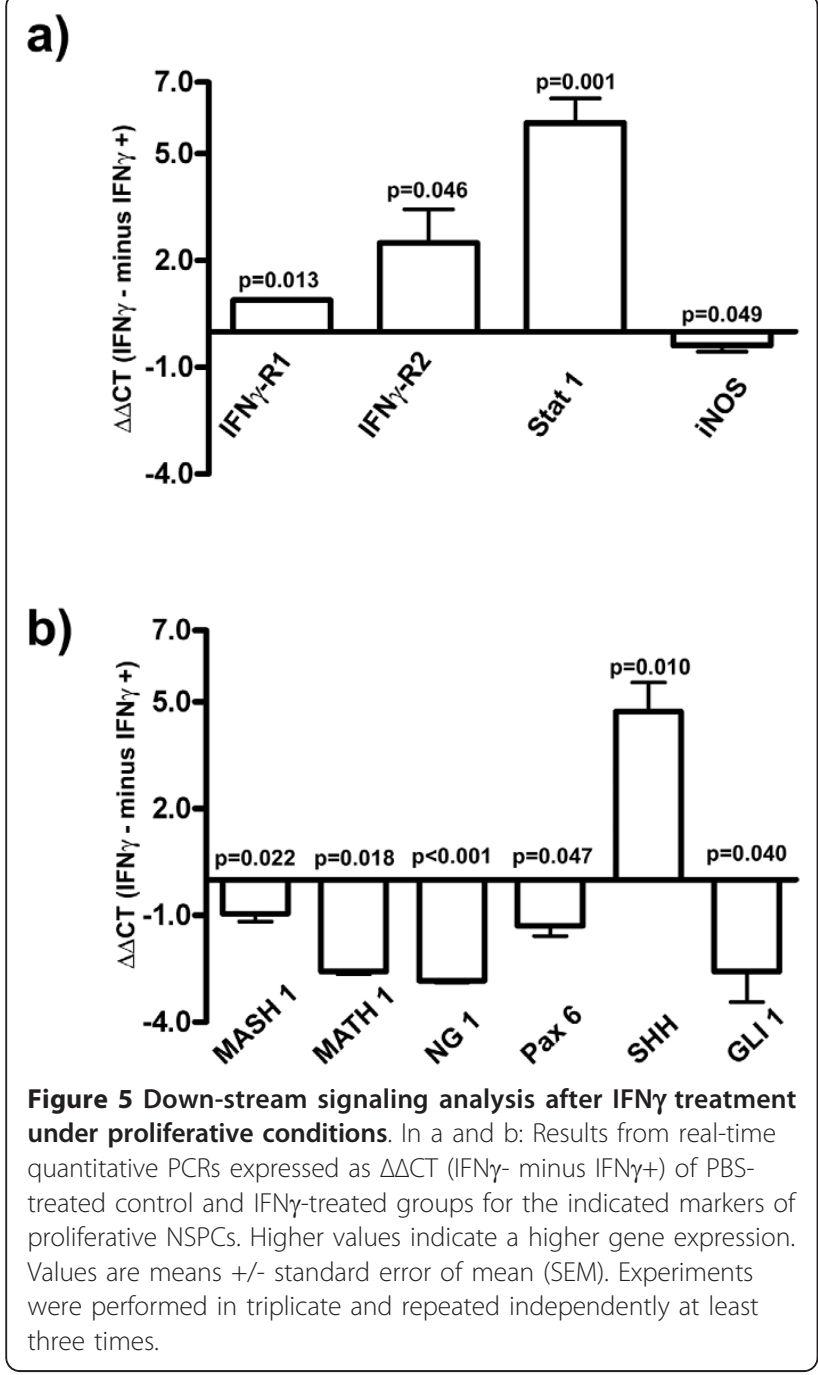

treatment significantly up-regulated SHH in NSPCs, Gli1 was down-regulated, an effect that was unanticipated (Figure 5B).

\section{$\mathrm{GFAP}^{+} / \beta \mathrm{III}-$ tubulin ${ }^{+}$cells exhibit non-neuronal and non- astrocytic functional properties}

To elucidate if the unusual effects of IFN $\gamma$ treatment on the differentiation of NSPCs are accompanied by an atypical functional phenotype, we next analyzed basic electrophysiological properties of $\mathrm{GFAP}^{+} / \beta \mathrm{III}-$ tubulin $^{+}$cells. For this purpose we combined whole-cell patch-clamp with subsequent immunocytochemistry to unambiguously identify recorded cells. $\mathrm{GFAP}^{+} / \beta$ III-tubulin ${ }^{+}$cells in IFN $\gamma$-treated proliferative $(n=5)$ or differentiated $(n=9)$ cultures almost exclusively exhibited an outward rectifying currentvoltage (IV) relationship (13/14 cells, Figure 6a-c). Small inward currents were observed in 4/14 cells (Figure 6d). When challenging $\mathrm{GFAP}^{+} / \beta I I I-$ tubulin ${ }^{+}$cells within differentiated cultures with current injections in current-clamp mode, none of these cells exhibited action potentials when depolarized to up to a membrane potential of approximately $+30 \mathrm{mV}(\mathrm{n}=7$, Figure $6 \mathrm{e}, \mathrm{f})$. GFAP ${ }^{+} / \beta \mathrm{HII}_{\text {-tubulin }}{ }^{-}$ cells in differentiated cultures either exhibited an outward rectifying IV relationship, similar to $\mathrm{GFAP}^{+} / \beta$ III-tubulin ${ }^{+}$ cells (3/6; Figure $6 \mathrm{~g}, \mathrm{~h}, \mathrm{i})$, or a linear IV-relationship that completely lacked voltage-dependent conductances $(\mathrm{n}=$ 3/6; Figure 6g, h, i). Such I/V relationships are typical for mature classical astrocytes [14] and were never observed in $\mathrm{GFAP}^{+} / \beta \mathrm{III}-$ tubulin ${ }^{+}$cells. Our electrophysiological results, thus, demonstrate that $\mathrm{GFAP}^{+} / \beta \mathrm{III}$-tubulin ${ }^{+}$cells are functionally distinct from mature astrocytes as well as neurons.

\section{IFN $\gamma$ treatment impaired the formation of in vitro- functional neural networks}

To ultimately verify the effect of IFN $\gamma$ on NSPC populations, we performed experiments using the microelectrode array (MEA) technology, that is able to detect functional neuronal network activity of entire neural populations. Immature ES cell-derived nSFEB aggregates consisting of a mixture of immature neural precursor cells were exposed to IFN $\gamma$ during their initial 7-day proliferation period under the influence of FGF-2. Hereafter, IFN $\gamma$ was removed and differentiation was initiated by FGF-2 withdrawal. By this paradigm, IFN $\gamma$ treatment selectively hit developmental processes of ES cell-derived NSPCs, while subsequent synapse formation and other maturational processes were excluded from direct IFN $\gamma$ influences. After the initial 7-day period, maturation of cultures was observed for additional 44 days. Normally, during the $3^{\text {rd }}$ and $4^{\text {th }}$ week, cultures start to develop functional neuronal networks that show increasing burst activity that finally ends in oscillating and synchronous neuronal network activity (Figure 7, IFN $\gamma$-). This synchrony of action potential bursts in spatially distributed neurons is expressed by the kappa value, with increasing values showing higher network synchrony. By this experiment we could show that a 7-day exposure to IFN $\gamma$ during a developmentally sensitive period of immature NSPCs under the influence of FGF-2 sustainably impairs the subsequent generation of functional neuronal networks as burstrate and kappa levels were significantly smaller in comparison to untreated populations (Figure 7). As neuronal network formation can also be impaired by low cell densities, we verified this factor under IFN $\gamma$ treated conditions. However, even though IFN $\gamma$ led to a reduced population extent, the 7-day proliferation period was by far sufficient to allow for the growth of morphologically dense and confluent neural cell populations.

\section{Discussion}

Our results shed new light on the effects of IFN $\gamma$ on NSPCs. Until now, IFN $\gamma$-related up-regulation of 
a) voltage-step-protocol

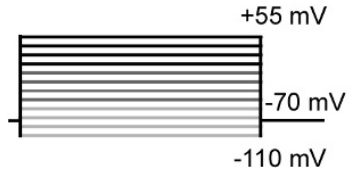

b) voltage clamp

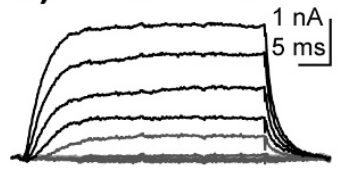

leak-subtracted
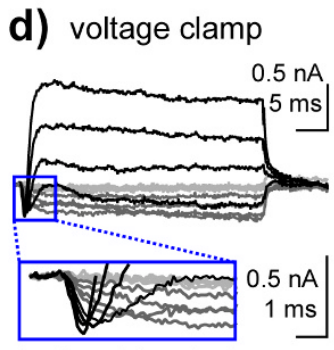

leak-subtracted
C) voltage clamp and IV relationship

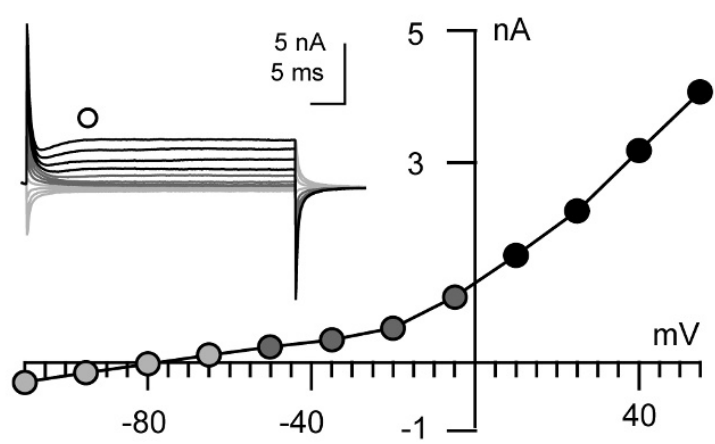

e)

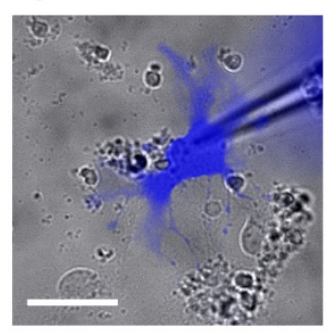

f) current clamp

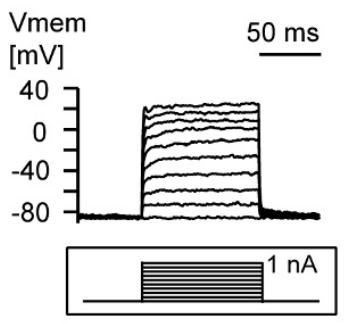

g) voltage clamp
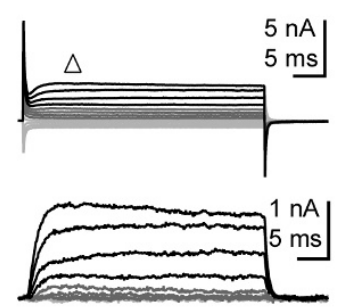

leak-subtracted h) voltage clamp

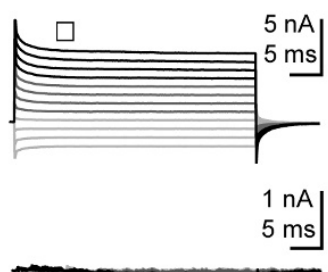

leak-subtracted i) IV relationship

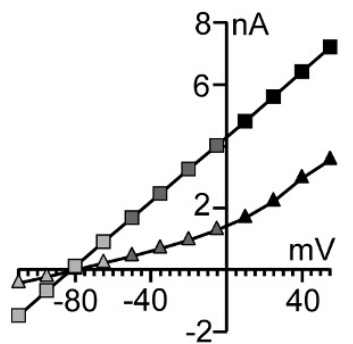

Figure 6 Patch-clamp results of IFN $\gamma$ treated NSPCs. In a: Voltage-step protocol used to probe cells for voltage-activated conductances (see current traces in panels b-d, g, and h). In b, c: GFAP / $\beta$ III-tubulin ${ }^{+}$cells typically exhibited an outward rectifying current voltage (IV) relationship (13/ 14 cells), IV-relationship was determined from non-leak-subtracted traces $10 \mathrm{~ms}$ after the voltage step (circle). In d: In $4 / 14 \mathrm{GFAP}^{+} / \beta \mathrm{lll}$-tubulin ${ }^{+}$cells, voltage-gated inward currents were observed in addition to outward currents. In e: Image of cell filled with Alexa Fluor350 and later identified as $\mathrm{GFAP}^{+} / \beta$ III-tubulin ${ }^{+}$(scale bar $30 \mu \mathrm{m}$, recordings illustrated in figure $\mathrm{d}$ ) and f). In f: None of the $14 \mathrm{GFAP}^{+} / \beta \| l$-tubulin ${ }^{+}$cells exhibited actionpotential-like events, upon depolarization to at least -30 mV evoked by current injections (inset). In g, h: Membrane currents typically observed in $\mathrm{GFAP}^{+} / \beta$ III-tubulin cells (each recorded in $3 / 6$ cells). In i: IV-relationships taken from non-leak-subtracted traces illustrated in g) (triangle) and h) (square).

$\beta$ III-tubulin was interpreted as a beneficial enhancement of neurogenesis [7-9]. The present study disproves this view and shows that IFN $\gamma$ instead promotes an abnormal NSPC-derived cellular phenotype that does not relate to classical neurons or astrocytes and that appears to be dysregulated in terms of functional and molecular properties. IFN $\gamma$ treatment leads to the expression of both, class III $\beta$ tubulin and GFAP in $\sim 40 \%$ of NSPC which is abnormal and, even after differentiation, not linked to mature neuronal or astrocytic electrophysiological function. Class III $\beta$ tubulin isotype is usually considered specific for post-mitotic neurons, and such aberrant expression has so far only been noted in gliomas $[15,16]$ or dysregulated tumorigenic neural stem cells $[17,18]$. Walton and colleagues even report some unusual coexpression of $\beta$ III-tubulin and GFAP in tumorigenic neural stem cells, a phenomenon similar to that detected here after IFN $\gamma$ treatment of regular NSPCs. The aspect of IFN $\gamma$-mediated NSPC dysregulation is further substantiated in the present report by an up-regulation of $\mathrm{SHH}$ which is paralleled by down-regulation of Gli1 which has been reported to be consistently up-regulated in the 


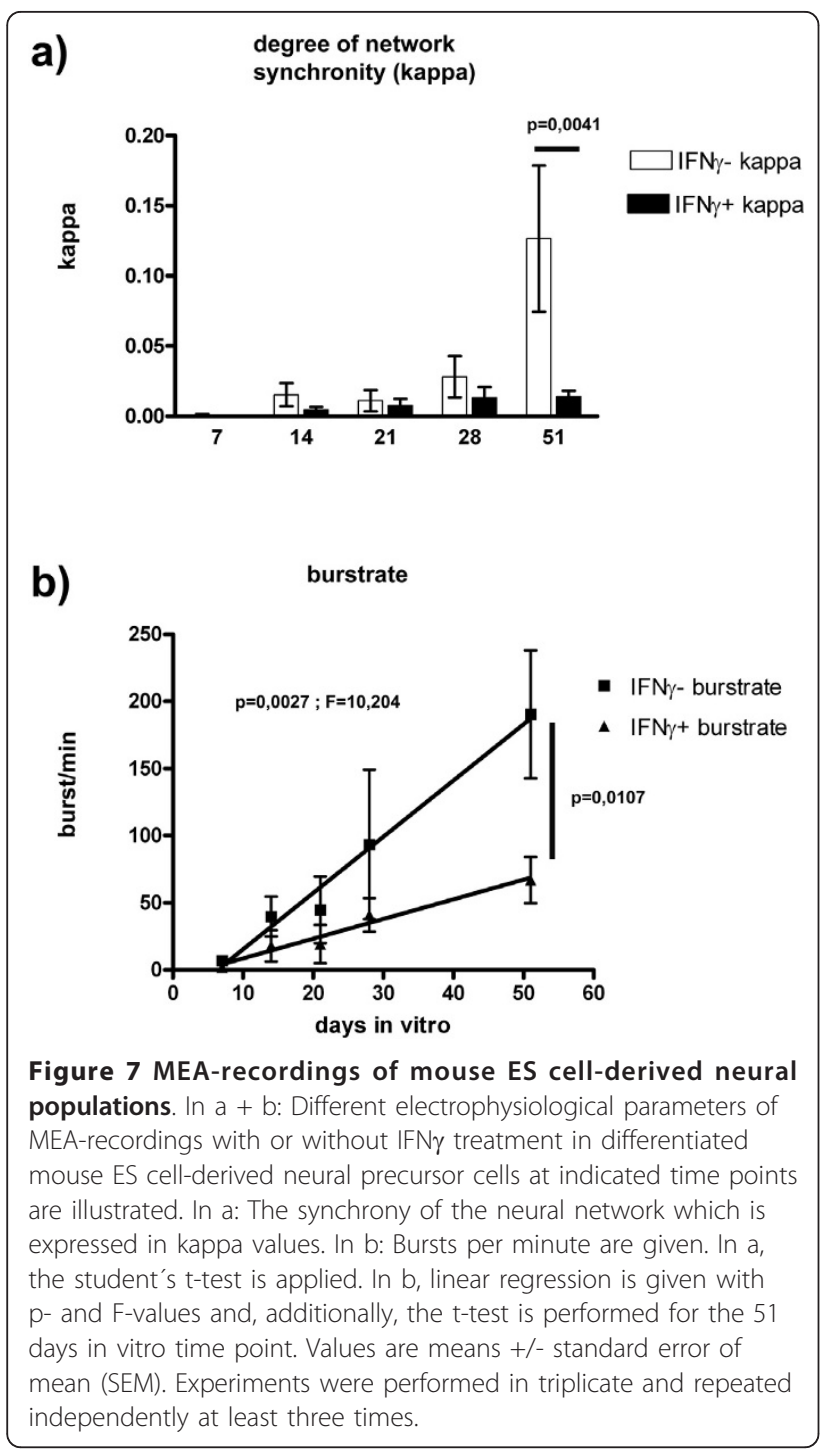

course of SHH signaling [19]. As expression patterns of neurogenic niche morphogenes like SHH or Gli1 are generally tightly regulated during CNS development, its disturbance points to misguided development or again tumorigenesis $[13,19]$. Thus, for the first time, we directly illustrated a possible link between IFN $\gamma$, NSPCs and cellular abnormalities similar to that observed in tumor cells strongly supporting the view that inflammation might be involved in tumor generation via neural stem cells. Additionally, the IFN $\gamma$-related down-regulation of iNOS in NSPC cultures is untypical as it is known that IFN $\gamma$ normally induces iNOS [20]. Our electrophysiological findings illustrate the importance of an additional functional control of morphological/immunocytochemical observations as the up-regulation of $\beta$ III-tubulin in differentiated NSPC-derived cells, which was interpreted as enhanced neurogenesis in different studies $[7,9]$, was not paralleled by neuronal electrophysiological behavior. Further, the increase in GFAP $/ \beta$ III-tubulin ${ }^{+}$neurons after IFN $\gamma$ treatment of proliferating cultures was not significant in the present study and after differentiation under the impact of IFN $\gamma$ we even found significantly less GFAP $^{-} / \beta$ III-tubulin ${ }^{+}$neurons. Interestingly, a similar observation was described previously [21]. We found that those $\beta$ III-tubulin expressing cells that significantly increased in numbers after IFN $\gamma$ treatment of proliferating or differentiating cultures were also GFAP positive and exhibited electrophysiological properties that were neither typical for mature astrocytes nor for neurons. We demonstrated this by careful correlating electrophysiological data of patched cells with their immunocytochemical phenotype. These molecular and functional IFN $\gamma$ effects on NSPCs indicate a profoundly compromised cell function or, alternatively, a new IFN $\gamma$-induced NSPC-derived neural cell of unknown function. Interestingly, ectopic expression of IFN $\gamma$ during early stages of CNS development induces medulloblastomas via $\mathrm{SHH}$ overexpression [13] pointing towards a general dysregulating effect of IFN $\gamma$ on NSPCs during development or disease.

To investigate functional neural development under controlled conditions, with and without IFN $\gamma$-treatment, we electrophysiologically measured the development of functional neuronal networks starting from ES cellderived immature neural precursor cell cultures. Usually, network activity progressively develops over time as a result of a complex interaction of a multitude of factors that converge to an integrated functional entity [22]. It depends on efficient synapse formation and function of an entire neuronal population. If using immature neural precursor populations as developmental starting point, basic aspects of functional neural development can be measured. In contrast, mature ES cell-derived functional neuronal networks can be used to detect acute functional consequences due to changes in extracellular composition. These investigations then affect already active neuronal networks. For instance, they showed to reversibly alter their network function under the influence of different cerebrospinal fluid specimens [23]. We chose a paradigm in which the influence of IFN $\gamma$ selectively affected the initial proliferation period of cultures that were subsequently held under normal differentiating conditions. IFN $\gamma$-treated cultures showed a significantly impaired development of neuronal network function, impressively pointing to an IFN $\gamma$-related, profoundly altered functional development of neural precursor populations.

\section{Conclusion}

Thus, we speculate that abnormally high IFN $\gamma$ production during development and CNS diseases might impair 
functional neuronal development in fetal neurogenesis or adult regeneration and propose to inhibit IFN $\gamma$ effects on NSPCs as a means to effectively support their developmental and regenerative potential.

\section{Materials and methods Neurosphere cultures}

Neurospheres were generated from fourteen-day-old wildtype C57BL/6J mouse embryos. Ganglionic eminences were removed, mechanically dissociated and seeded in DMEM/F12 culture medium (1:1; Invitrogen, Karlsruhe, Germany) containing 0.6\% Glucose (Sigma-Aldrich, Hamburg, Germany), glutamine (2 mM; Invitrogen), sodium bicarbonate (3 mM; Invitrogen), Hepes buffer ( $5 \mathrm{mM}$; Invitrogen) and B27 (20 $\mu \mathrm{l}$ per ml; Invitrogen). For generation and expansion of neurosphere cells, epidermal growth factor (EGF) (Tebu-bio, Le Perray en Yvelines Cedex, France) and basic fibroblast growth factor-2 (FGF-2) (Tebu-bio) were added to a final concentration of $20 \mathrm{ng}$ per ml each.

\section{Generation of embryonic stem cell-derived neural stem cells}

Undifferentiated ES cells (SV-129, ATCC, Millipore, Billerica, USA) were grown under feeder-deprived conditions in the presence of $1000 \mathrm{U} / \mathrm{ml}$ leukemia inhibitory factor (LIF, Millipore) and 20\% fetal bovine serum (FBS, HyClone, Thermo Fisher Scientific, Schwerte, Germany) in ES cell medium described elsewhere [24]. Neural differentiation of immature ES cells into neural stem cell (NS cells) was performed according to modified protocols [22,25].

\section{IFN $\gamma$ treatment and immunocytochemistry}

For immunocytochemistry, neurosphere cells or ES cellderived NS cells were dissociated to a single cell suspension and plated on poly-L-ornithine (PLO; 0.001\%; Sigma-Aldrich) and fibronectin $(5 \mu \mathrm{g} / \mathrm{ml}$; Tebu-bio) coated cover slips (VWR International, Darmstadt, Germany) at a density of $50 \times 10^{3}$ cells per ml. After 3 days under the influence of EGF and FGF-2 $(20 \mathrm{ng} / \mathrm{ml}$ both Tebu-bio), cells were assigned to the different experimental groups. To verify the marker expression of undifferentiated (proliferating) neural populations under control or IFN $\gamma$ treated conditions, cultures were kept under the influence of EGF/FGF-2 without or with IFN $\gamma$ (1000 U/ml; Millipore) until fixation after further 3 days (NSPC-p -IFN $\gamma /+$ IFN $\gamma$ ). To verify cell-type specific marker expression in differentiated cultures, growth factors were withdrawn and then, cells were treated for 7 days without or with IFN $\gamma$ until fixation (NSPC-d -IFN $\gamma$ / + IFN $\gamma$ ). For control experiments, only phosphate-buffered saline solution (PBS; 1X; Invitrogen) was added to the medium. Primary antibodies used at $4{ }^{\circ} \mathrm{C}$ overnight were monoclonal mouse antibodies to 5-bromo-2-deoxyuridine (BrdU; 1:1000, Sigma-Aldrich), $\beta$ III-tubulin (Tuj1; 1:500; R\&D Systems, Minneapolis, USA or 1:800, Abcam, Cambridge, UK), Map2a-c (1:2000; SigmaAldrich), Sox2 (1:50; R\&D Systems), IFN $\gamma-R 1$ (1:500; Santa Cruz Biotechnology) and beta Actin (1:100; Millipore) and polyclonal rabbit antibodies to glial fibrillaric acid protein (GFAP) (1:500; Dako, Hamburg, Germany or 1:1000; Abcam), caspase (1:100; Cell Signaling), IFN $\gamma$-R2 (1:500; Santa Cruz Biotechnology) and nestin (1:200; Covance). BrdU labeling is described elsewhere (Wellen et al., 2009). For detection of primary antibodies, fluoresceine-isothiocyanate (FITC; 1:500; Millipore) and indocarbocyanine (Cy3; 1:800; or Cy5; 1:200; Millipore) coupled secondary antibodies were used. For negative controls, primary antibodies were omitted in each experiment. To measure the total population of cells, Dapi positive cell nuclei were counted. On every cover slip, at least 100 cells were counted.

\section{MTT-Assay}

To analyze the population extent of NSPCs, the optical density [9], indicative of conversion of 3-(4, 5dimethylthiazol-2-yl)-2, 5-diphenyltetrazolium bromide (MTT; Sigma-Aldrich) into formazan crystals which takes place in live cells only, was determined after IFN $\gamma$ treatment at decreasing concentrations as indicated. An OD value of 0.5 represents approximately 50,000 , and an OD value of 1.0 represents approximately 100,000 live NSPCs. The population extent was measured after 48 hours of IFN $\gamma$ treatment as indicated.

\section{Caspase-activity Assay}

For detection of caspase 3/7 activity after IFN $\gamma$ treatment, we used the Caspase-Glo 3/7 assay (Promega, Madison, USA). Proliferating cultures were treated with decreasing concentrations of IFN $\gamma$ as indicated. Adding the assay components to cultivated cells leads to cell lysis and release of caspase $3 / 7$. Caspase $3 / 7$ is capable of cleaving a tetrapeptide sequence substrate; this is dismantled by luciferase which is a component of the assay. The resulting light emission is then a measure of caspase activity.

\section{Quantitative real-time PCR}

RNeasy Kit (Qiagen) was used for RNA isolation of cultured NSPCs. Then a reverse transcription into cDNA (ABI, Darmstadt, Germany) was performed. Quantitative real-time PCR was carried out by the usage of the 7500 fast or 7500 quantitative real-time PCR cycler (ABI, Darmstadt, Germany). Either SYBR green master mix 
(Qiagen) or equivalent chemistry from another supplier (Quantace, London, UK) was used. The specific primer for genes of interest or the housekeeping gene (glyceraldehyde-3-phosphate dehydrogenase, GAPDH) was either purchased (QuantiTect primer assays, Qiagen) or self designed (BioTEZ, Berlin, Germany). The genes of interest (target gene) in IFN $\gamma$-treated groups or control groups (PBS-treated) were analyzed in at least 3 independent cultures in triplicate each. Every experiment in IFN $\gamma$-treated or control (PBS-treated) groups provided delta $\mathrm{CT}$ values $(\triangle \mathrm{CT}$ : gene of interest minus housekeeping gene). The presented graphs are $\Delta \Delta C \mathrm{C}$ values:

$$
\begin{array}{r}
\Delta \Delta \mathrm{CT}=\left(\mathrm{Ct}_{\text {target gene }} \mathrm{Ct}_{\text {housekeeping gene }}\right)_{\text {PBS-treated }} \\
-\left(\mathrm{Ct}_{\text {target gene }}-\mathrm{Ct}_{\text {housekeeping gene }}\right)_{\text {IFN } \gamma \text {-treated }}
\end{array}
$$

\section{Patch-clamp recordings}

Somatic whole-cell patch-clamp recordings were carried out using an Axopatch 200B amplifier (Molecular Devices, Sunnyvale, CA, USA) coupled to a personal computer via a digidata 1322A interface (Molecular Devices). Data were acquired at $10 \mathrm{kHz}$ using PClamp 8.2 software (Molecular Devices). Patch pipettes were pulled from borosilicate glass (Hilgenberg, Waldkappel, Germany) and had a resistance of 3-6 $\mathrm{M} \Omega$ when filled with intracellular solution containing (in $\mathrm{mM}$ ): $120 \mathrm{~K}$ $\mathrm{MeSO}_{3}, 32 \mathrm{KCl}, 10 \mathrm{HEPES}$ (N-(2-Hydroxyethyl)piperazine-N'-(2-ethanesulfonic acid), $4 \mathrm{NaCl}, 4 \mathrm{Mg}$-ATP and 0.4 Na-GTP, 1 Alexa Fluor 350 (Molecular Probes/Invitrogen), pH 7.30 (calculated liquid junction potential: $12.5 \mathrm{mV}$ ). Cells were held at membrane potentials of $-70 \mathrm{mV}$. To separate passive conductances from voltagegated currents, online leak subtraction $(\mathrm{P} / 4)$ was performed. Extracellular solution during patch-clamp experiments contained in mM: $125 \mathrm{NaCl}, 2.5 \mathrm{KCl}, 2$ $\mathrm{CaCl}_{2}, 1 \mathrm{MgCl}_{2}, 1.25 \mathrm{NaH}_{2} \mathrm{PO}_{4}, 26 \mathrm{NaHCO}_{3}$, and 20 glucose, bubbled with $95 \% \mathrm{O}_{2}$ and $5 \% \mathrm{CO}_{2}$ to result in a $\mathrm{pH}$ of 7.4. Patch-clamp data were processed and analyzed using IGOR Pro-Software (WaveMetrics, Inc., Lake Oswego, OR). After the recordings, patch-pipettes were carefully withdrawn and coverslips were transferred into $4 \%$ paraformaldehyde for 20 minutes at room temperature. Thereafter coverslips were kept in PBS (Invitrogen) at $4{ }^{\circ} \mathrm{C}$ until they were processed for GFAP and $\beta$ tubulin immunocytochemistry. By means of fluorescence at $350 \mathrm{~nm}$ electrophysiologically recorded cells were identified and assigned either to $\mathrm{GFAP}^{+} / \beta \mathrm{III}-$ tubulin $^{+}$or $\mathrm{GFAP}^{+} / \beta \mathrm{III}-$ tubulin ${ }^{-}$cells.

\section{Microelectrode array recordings}

For microelectrode array (MEA) recordings, 5 to 10 neural precursor cell-enriched, serum-free, floating embryoid body-like aggregates (nSFEBs) [22] were seeded on poly-D-lysine (PDL, $15 \mu \mathrm{g} / \mathrm{ml}$, Sigma-Aldrich, Germany) and laminin $(15 \mu \mathrm{g} / \mathrm{ml}$, Sigma-Aldrich, Germany) coated MEAs with a square grid of 60 planar Ti/ TiN electrodes (30- $\mu \mathrm{m}$ diameter, 200- $\mu \mathrm{m}$ spacing) and an input impedance of $<50 \mathrm{kU}$ according to the specifications of the manufacturer (Multi Channel Systems, Reutlingen, Germany). Signals from all 60 electrodes were simultaneously sampled at $25 \mathrm{kHz}$, visualized and stored using the standard software MC Rack provided by Multi Channel Systems. Spike and burst detection was performed off-line by custom-built software (Result, Düsseldorf, Germany). nSFEBs were kept for 7 days after plating under the influence of FGF-2 $(20 \mathrm{ng} / \mathrm{ml}$, PeproTech) only (IFN- $\gamma$ - group) or together with IFN- $\gamma$ (1000 U/ml; IFN- $\gamma+$ group). After 7 days, FGF-2 and IFN- $\gamma$ were removed from the medium to induce terminal differentiation. For long-term culture, ES cellderived neuronal networks were kept in DMEM/F12 (Gibco) supplemented with N2, B27 and Glutamax (all Invitrogen). MEA recordings were performed at the indicated time points.

\section{Statistical analyses}

Experiments were repeated with independent cultures at least three times in triplicate each. The resulting data sets were statistically analyzed und illustrated using the GraphPad Prism 4 (GraphPad Software Inc., San Diego, CA, USA, 2003) software. For approval of statistical significance between groups a two-tailed t-test was performed. $P$ values $<0.05$ were considered to indicate significant differences. For comparison of functional neuronal network development, slopes of linear regressions were calculated with GraphPad Prism 4 and pand F-values were given.

\section{Acknowledgements}

We are grateful to Sabine Hamm and Christine Holland for excellent technical assistance, animal care and laboratory support.

\section{Competing interests}

The authors declare that they have no competing interests.

\section{Authors' contributions to the manuscript}

MD and JW conceived and designed the manuscript. MD supported the study financially. HPH supported the study administratively. JW, SDH, SI and JMW collected and assembled the data. JW and MD wrote the manuscript. The manuscript was finally approved by MD, HPH and CRR. CRR conceived and afforded the patch clamp recordings. SDH performed and analysed the patch clamp recordings. SI performed the MEA recordings.

All authors read and approved the final manuscript.

\section{Author details}

'Department of Neurology, Heinrich-Heine-University, Moorenstr. 5, 40225 Düsseldorf, Germany. ${ }^{2}$ Institute for Neurobiology, Heinrich-Heine-University, Universitätsstr. 1, 40225 Düsseldorf, Germany. ${ }^{3}$ Dept. of Neurophysiology, Center for Brain Research, Medical University of Vienna, Spitalgasse 4, 1090 Vienna, Austria. 
Received: 6 October 2010 Accepted: 3 March 2011

Published: 3 March 2011

\section{References}

1. Bjorklund A, Lindvall O: Cell replacement therapies for central nervous system disorders. Nat Neurosci 2000, 3:537-544.

2. Lucas SM, Rothwell NJ, Gibson RM: The role of inflammation in CNS injury and disease. Br J Pharmacol 2006, 147(Suppl 1):S232-240.

3. Schmitz T, Chew L: Cytokines and myelination in the central nervous system. ScientificWorldJournal 2008, 8:1119-1147.

4. Liesz A, Suri-Payer E, Veltkamp C, Doerr H, Sommer C, Rivest S, Giese T, Veltkamp R: Regulatory $T$ cells are key cerebroprotective immunomodulators in acute experimental stroke. Nat Med 2009, 15:192-199.

5. Lees JR, Golumbek PT, Sim J, Dorsey D, Russell JH: Regional CNS responses to IFN-gamma determine lesion localization patterns during EAE pathogenesis. J Exp Med 2008, 205:2633-2642.

6. Butovsky O, Ziv Y, Schwartz A, Landa G, Talpalar AE, Pluchino S, Martino G, Schwartz M: Microglia activated by IL-4 or IFN-gamma differentially induce neurogenesis and oligodendrogenesis from adult stem/ progenitor cells. Mol Cell Neurosci 2006, 31:149-160.

7. Whitney NP, Eidem TM, Peng H, Huang Y, Zheng JC: Inflammation mediates varying effects in neurogenesis: relevance to the pathogenesis of brain injury and neurodegenerative disorders. J Neurochem 2009, 108:1343-1359.

8. Baron R, Nemirovsky A, Harpaz I, Cohen H, Owens T, Monsonego A: IFNgamma enhances neurogenesis in wild-type mice and in a mouse model of Alzheimer's disease. Faseb J 2008, 22:2843-2852

9. Johansson S, Price J, Modo M: Effect of inflammatory cytokines on major histocompatibility complex expression and differentiation of human neural stem/progenitor cells. Stem Cells 2008, 26:2444-2454.

10. Wang J, Lin W, Popko B, Campbell IL: Inducible production of interferongamma in the developing brain causes cerebellar dysplasia with activation of the Sonic hedgehog pathway. Mol Cell Neurosci 2004 27:489-496.

11. LaFerla FM, Sugarman MC, Lane TE, Leissring MA: Regional hypomyelination and dysplasia in transgenic mice with astrocytedirected expression of interferon-gamma. J Mol Neurosci 2000, 15:45-59.

12. Kim IJ, Beck HN, Lein PJ, Higgins D: Interferon gamma induces retrograde dendritic retraction and inhibits synapse formation. J Neurosci 2002, 22:4530-4539.

13. Lin W, Kemper A, McCarthy KD, Pytel P, Wang JP, Campbell IL, Utset MF, Popko B: Interferon-gamma induced medulloblastoma in the developing cerebellum. J Neurosci 2004, 24:10074-10083.

14. Zhou M, Schools GP, Kimelberg HK: Development of GLAST(+) astrocytes and $\mathrm{NG2}(+)$ glia in rat hippocampus CA1: mature astrocytes are electrophysiologically passive. J Neurophysiol 2006, 95:134-143.

15. Ignatova TN, Kukekov VG, Laywell ED, Suslov ON, Vrionis FD, Steindler DA: Human cortical glial tumors contain neural stem-like cells expressing astroglial and neuronal markers in vitro. Glia 2002, 39:193-206.

16. Katsetos CD, Del Valle L, Geddes JF, Assimakopoulou M, Legido A, Boyd JC, Balin B, Parikh NA, Maraziotis T, de Chadarevian JP, et al: Aberrant localization of the neuronal class III beta-tubulin in astrocytomas. Arch Pathol Lab Med 2001, 125:613-624.

17. Walton NM, Snyder GE, Park D, Kobeissy F, Scheffler B, Steindler DA: Gliotypic neural stem cells transiently adopt tumorigenic properties during normal differentiation. Stem Cells 2009, 27:280-289.

18. Singh SK, Clarke ID, Terasaki M, Bonn VE, Hawkins C, Squire J, Dirks PB: Identification of a cancer stem cell in human brain tumors. Cancer Res 2003, 63:5821-5828.

19. Stecca B, Ruiz i Altaba A: Brain as a paradigm of organ growth: Hedgehog-Gli signaling in neural stem cells and brain tumors. J Neurobiol 2005, 64:476-490.

20. Bach EA, Aguet M, Schreiber RD: The IFN gamma receptor: a paradigm for cytokine receptor signaling. Annu Rev Immunol 1997, 15:563-591.

21. Wang Y, Imitola J, Rasmussen S, O'Connor KC, Khoury SJ: Paradoxical dysregulation of the neural stem cell pathway sonic hedgehog-Gli1 in autoimmune encephalomyelitis and multiple sclerosis. Ann Neurol 2008, 64:417-427.
22. Illes $S$, Theiss $S$, Hartung HP, Siebler M, Dihne M: Niche-dependent development of functional neuronal networks from embryonic stem cell-derived neural populations. BMC Neurosci 2009, 10:93.

23. Otto F, Illes S, Opatz J, Laryea M, Theiss S, Hartung HP, Schnitzler A, Siebler M, Dihne M: Cerebrospinal fluid of brain trauma patients inhibits in vitro neuronal network function via NMDA receptors. Ann Neurol 2009, 66:546-555.

24. Okabe S, Forsberg-Nilsson K, Spiro AC, Segal M, McKay RD: Development of neuronal precursor cells and functional postmitotic neurons from embryonic stem cells in vitro. Mech Dev 1996, 59:89-102.

25. Conti L, Pollard SM, Gorba T, Reitano E, Toselli M, Biella G, Sun Y, Sanzone S, Ying QL, Cattaneo E, Smith A: Niche-independent symmetrical selfrenewal of a mammalian tissue stem cell. PLoS Biol 2005, 3:e283.

doi:10.1186/1750-1326-6-18

Cite this article as: Walter et al:: A new role for interferon gamma in neural stem/precursor cell dysregulation. Molecular Neurodegeneration 2011 6:18.

\section{Submit your next manuscript to BioMed Central and take full advantage of:}

- Convenient online submission

- Thorough peer review

- No space constraints or color figure charges

- Immediate publication on acceptance

- Inclusion in PubMed, CAS, Scopus and Google Scholar

- Research which is freely available for redistribution

Submit your manuscript at www.biomedcentral.com/submit
C Biomed Central 